\title{
Undergraduate Research in Engineering Technology as a High-Impact Learning Experience
}

\author{
Ilse Nava-Medina, Angie Hill Price, Mathew Kuttolamadom \\ inavamed@email.tamu.edu, price@tamu.edu, mathew@tamu.edu \\ Texas A\&M University
}

\begin{abstract}
The objective of this paper is to explore various formats of undergraduate research as high-impact learning experiences within engineering technology programs, and specifically in a Manufacturing and Mechanical Engineering Technology degree offered at Texas A\&M University. Though undergraduate research is identified by the Association of American Colleges and Universities as a high-impact educational practice, it is not commonly encouraged or pursued within engineering technology programs (as compared to engineering programs) predominantly due to the hands-on and experiential nature of the curriculum. This paper will outline and compare the different types of undergraduate research activities pursued by various students within this engineering technology program; these include single and multi-semester individual and group research projects, accelerated projects over summer sessions with and without university-level schedules/organization, projects having participants from multiple departments, research as part of honors theses, research involving exchange students and/or multi-location projects, and research project topics having a primarily hands-on nature vs. hypothesizing/fundamental research. The paper will conclude with reporting and reflecting on their experiences and feedback, the effectiveness of the activities as high-impact learning experiences, the lessons learned, and best practices moving forward.
\end{abstract}

\section{Keywords}

Undergraduate research, Engineering technology, High-impact learning, Honors thesis, Hands-on.

\section{Introduction}

Engineering technology programs generally have curricula that are very hands-on and experiential in nature. As a result, research projects/problems, and more specifically, hypothesis-driven or fundamental research is generally not conducted or encouraged to a large extent as part the degree. Such a practice is not because engineering technology students do not have the aptitude for conducting research, but rather the constraints of coursework and the associated laboratory practice largely prohibits it from a time/resource standpoint. Tackling a research problem as a high-impact learning experience will be especially beneficial to engineering technology students since many of the solutions that they are tasked to seek out as part of their normal job responsibilities involve the activities of inquiry, hypothesizing, reasoning, etc., in other words, essential components of research.

This paper is an exploration of the various types/formats of research programs pursued by engineering technology students in the Manufacturing and Mechanical Engineering Technology 
(MMET) program at Texas A\&M University, and a reflection of their experiences and the feedback obtained. Conducted either as individual or group projects, as well as those tackling hands-on vs. fundamental problems, the response from this select group of students was that they had a very positive experience, and for some it even reinforced their decisions to pursue graduate school.

\title{
Background
}

Different types of engineering and engineering technology undergraduate research experiences have been offered from the NSF Research Experiences for Undergraduate summer programs to small individual projects undertaken during the semester. Research indicates that numerous benefits from undergraduate research accrue to the student as well as to the sponsoring faculty member.

As noted by Zhan et al, faculty in engineering technology do not typically have access to graduate students for research, but they are expected increasingly to engage in greater amounts of research and scholarly work. ${ }^{1}$ Using undergraduates to support research benefits the students, but also can advantage the faculty member through support of the research agenda, and through curriculum improvement. Engineering technology students working in this program gained multi-disciplinary technical knowledge and improvement in their communication skills. A benefit to the department resulted when the participants in undergraduate research became proponents of the experience, and encourages classmates to engage in undergraduate research. The students also used the research as a vehicle to recruit students into the program.

Continuous curriculum improvement and the preparation for life-long learning are challenges for all faculty members; undergraduate research can support this effort. Robertson discussed innovative ways of using aspects of undergraduate research in the curriculum to improve learning. ${ }^{2}$ By requiring students to write small scale research proposals based on hand on research experience, students were encouraged to discover independently new technology and advances in the study of current literature. Students with the research experience were better prepared for later capstone coursework. The improvement in critical thinking is a benefit to the student ${ }^{3,4}$, and is a part of the high impact learning experience which leads to life-long learning capabilities.

One challenge for the faculty is recruiting students into undergraduate research programs from majors such as engineering technology. As Branch et al discovered, students who were not originally drawn to participate are more likely to do so when they were recruited by the faculty members. Female students were more likely to be more receptive to participate if they were personally addressed and encouraged by the faculty member. ${ }^{5}$ This indicates that faculty must not rely upon students to approach them but actively engage a wide array of students in the research enterprise. Altruger et al found that social implications of research were motivating to students in the engagement of research. ${ }^{6}$

As hand-on activities are embedded in the engineering technology curriculum, these types of research activities are very attractive to their students. Altruger, et al allowed students to fabricate and validate systems as part of the undergraduate research experience. ${ }^{6}$ Tangible benefits to the students from the experience included scholarships and internships. Okhio et al notes that hands on research experiences helped to "foster a sense of accomplishment." In one program, students are motivated through participation in national competitions that include a build aspect, even beginning

\author{
Proceedings of the 2017 ASEE Gulf-Southwest Section Annual Conference \\ Organized by The University of Texas at Dallas \\ Copyright $\odot$ 2017, American Society for Engineering Education
}


at the freshman level. ${ }^{8}$ The hands on skills were noted as specific contributions by the engineering technology students to a research team including engineering student. ${ }^{9}$ Several authors noted various benefits perceived by the student researchers such as interactions between the students and the faculty, increased confidence and improved resumes. ${ }^{9,10,11}$

Reisel et al studied the average student who isn't likely to be going to graduate school, but participated in an undergraduate research experience. ${ }^{4}$ This is typical of most engineering technology students, who are primarily preparing for careers in industry. Though the authors of this particular study found that the undergraduate research increased teamwork abilities, they also discovered that the students perceived an increase in their ability to work independently. The student self-perceptions as to the benefits of undergraduate research also included an improvement in problem solving abilities and in how to do research, and a better relationship with faculty members. The overall satisfaction with undergraduate research was dependent upon the faculty advisor. The researchers defined a successful undergraduate research experience (URE) as one that met the following:

“1) The URE should develop applied engineering, critical thinking, and problem solving skills of the students to help prepare them for a career as an engineer, likely in industry.

2) The URE should improve the communication skills of the student.

3) The URE should increase the confidence of the student in their abilities, and help clarify their career goals.

4) The URE should both help the student learn to work independently and as part of a team.

5) The URE should provide the students with an understanding of how to conduct a research project." 4

\section{Types of Undergraduate Research Programs and Student Feedback}

The different types of undergraduate research activities pursued by various students within this engineering technology program and the reflection of their experiences is outlined and compared.

\section{Single/Multi-Semester Individual Research Projects}

In this type of research projects, a number of students out of their own initiative or due to (passive) encouragement from their professors, initiated contact with a professor who worked in their general technical area of interest. This is not the norm for undergraduate students in engineering technology since research projects/credits are currently not part of the curricula in any form. Such initial contact, which typically lasted from one to three face-to-face meetings, was meant to gain more information on the research topic, the expectations, timeline, etc., and overall was meant to gauge the suitability and feasibility of the project/topic for each individual. As expected, there was no dearth of interest or aptitude. One of the major hindrances for committing to a project was the lack of available student time, given their full-load lecture and laboratory schedules sometimes extending into the late evening hours as well as their non-academic on/off-campus workloads. The students who felt that they had some hours to spare each week committed to a research project. Regarding research topics, the only trepidation was along the lines of their own technical capabilities/skills pertaining to the research project, and especially since this was their generally first experience with research. Once the major 'fears' were alleviated that included self-competency concerns and the uncertainties involved, the students were excited to get started and get the major equipment/safety training done.

\section{Proceedings of the 2017 ASEE Gulf-Southwest Section Annual Conference \\ Organized by The University of Texas at Dallas \\ Copyright $($ 2017, American Society for Engineering Education}


Besides completing the relevant equipment/safety training, one of the most important initial details involved planning and laying out a timeline of goals, tasks, contingency plans and deliverables. This guided exercise was crucial to lay out a work plan as well as to align expectations. The timeline involved most major steps of research including preliminary testing and data analyses, literature review, hypothesizing, prototyping, validating, etc. Guidance/advising was in the form of about an hour long face-to-face meeting each week; students were encouraged to set up additional meetings or drop by the faculty office as needed, or call the faculty to the lab if needed. The students were given autonomy in their work hours with constraints in the form of weekly deliverables. Faculty guidance was predominantly to aid in making major research project decisions as well as to facilitate access to auxiliary facilities and other affiliated labs. Significant emphasis was placed on logging the data and contributing weekly to the major final deliverables such as a report, conference/journal paper or poster. When closer to the public dissemination deadline, students had the opportunity to practice their presentations within the larger faculty research group, and ample feedback and pointers were provided for betting their mode of public dissemination. Student projects concluded with the turning in of all relevant data, samples and other media related to the project.

The majority of the research projects were intended to be one semester long ( 4 months) projects, with the possibility of extending to another semester to pursue the next phase of the project, pending student time availability. Having had a number of students go through single-semester and twosemester projects, no significant difference was observed between the performance and experience of these two student groups. For two-semester project students, a timeline of tasks and deliverables were outlined for each of the two semesters. These students were able to complete the second phase of the project and their major final deliverable (poster, paper, etc.) had a more detailed treatment of the research topic.

Altogether, the students generally had a fulfilling experience through these research projects. Some of the only delays/concerns involved coordinating with the schedule of other shared/affiliated laboratory staff and students as well as machine availability times. Most of the students took ownership of their projects and were quite proud to display their final deliverables. Many expressed interest to continue on with their projects once their schedules/workloads could accommodate the project in future semesters. Also, graduating seniors expressed interest and less uncertainty about pursuing graduate school or other advanced-level courses.

\section{Single/Multi-Semester Group Research Projects}

This type of projects typically involved 2 or more students from a single or multiple departments who were collectively committed to a particular research project. The most common format was a pair of complementing students, and in some cases, there were 10 member teams with student participants spanning 4 different engineering departments. Students were either recruited within a multi-member team right from the beginning or individual students who expressed interest were grouped within a suitable team. In some cases individual students within a team had non-inclusive but related tasks contributing to the common larger goal, and in others, multiple students were tasked with completing a common set of tasks.

Altogether, it was generally observed that student groups performed very effectively as compared to individual research projects, except in case of highly-driven students pursuing individual research projects. Since there were multiple students within each team, these student groups had the advantage of being able to accommodate a variety of work schedules, besides brining to the table 
complementing sets of technical knowledge and skills. Further, they served to motivate other members of the team and were able to maintain the intended schedule of tasks more effectively, besides being able to disseminate knowledge and clarify concepts across the team. It should be mentioned that in the case of large teams ( 10 members), there was usually a graduate student mentor who served to coordinate individual/team activities and progress, and this graduate student along with the undergraduate team members would report to the faculty mentor(s).

Accelerated Summer Projects with/without University Support and/or Involving Exchange Students This type of projects included those with durations lasting one summer session ( 6 weeks) or both summer sessions ( $\sim 3$ months). The participant students were either registered for light course loads (1-2 courses), or were not taking classes during summer. Some of the students were pursuing nonacademic hourly employment during this time as well. The students were not provided a stipend by the faculty advisor(s), however, some of the students were provided a weekly/biweekly stipend by their respective departments or the summer research programs they were participating through.

Some of the students' working schedules were set in accordance with the goals collectively agreed with their faculty mentors. There were other groups of students who had a college/university-level schedule to satisfy as well which included professional development workshops (resume, job search, interview workshops, etc.), brown-bag lunch series, as well as small career development assignments to complete including preparing a resume, career portfolio, etc. In addition, these students were also instructed to work with their faculty mentors to develop research project-based deliverables such as an abstract, work plan, progress reports, final posters/papers, presentations, etc.

Besides having undergraduate students internal to the university, a number of exchange or visiting students were also involved in such projects. These included students working under the National Science Foundation (NSF) Research Experiences for Undergraduates (REU) framework, international students funded by their respective countries' education/exchange organizations that had bilateral ties with the United States, domestic students from other universities across the nation as well as from within the Texas A\&M university system that had collaborative ties with Texas A\&M University, and other domestic students that had applied to Texas A\&M University to take part in the Undergraduate Summer Research Grant (USRG) programs. Additionally, this group also included students that were part of an innovative REU program that involved one faculty mentor and one undergraduate student each from both Texas A\&M University and a partner university (viz., Pennsylvania State University) working on a collaborative research project, and spending $\sim 6$ weeks each at both locations.

Since there were relatively fast-paced programs (as compared to the regular semesters), a detailed timeline that included contingency plans, concurrent activities, and tasks to complete during the inevitable or unexpected downtimes was set at the beginning of the programs to make sure the project proceeded according to the timeline. Also, meeting times were relatively flexible with at least one or two student meetings with the faculty advisors each week. Since most of the students did not have regular classes during this time, having such meetings each week was meant to provide some form of a helpful structure and deadlines to the students.

Overall, students both internal and external (visiting) to the university were quite excited about their summer research experiences. For many, it was their first real exposure to research, its intricacies and uncertainties and training/learning on the go, as well as exposure to a new university 
environment and setting. They were also quite proud to publically disseminate their research findings in the form of posters/papers and presentations, besides being able to list and talk about a state-of-the-art research experience in their resumes as well in future job interviews. As in the case of regular semester research project students, many of them expressed interest in continuing on with their respective projects in the future as well as in obtaining a clearer picture of a graduate school experience.

Research as Part of Honors Theses (Hands-On Nature vs. Hypothesizing/Fundamental Research) This group of research projects/students took on formal undergraduate honors research theses, and was able to experience a research program that was closest in experience to completing a graduate master's thesis. Most of the students were students who were committed and already inclined to conduct research and potentially purse graduate school.

As part of a university wide honors and undergraduate research program (part of Undergraduate Studies within the Division of Academic Affairs), this involved academically high-performing students contacting professors on their own initiative or professors identifying and recruiting students with suitable potential and research aptitude to be part of the program. This is a twosemester research program that asks for the students' commitment in the form of a 'contract' and holds them to high standards of excellence and responsibility. These undergraduate research scholars had to first identify and gain agreement from a suitable faculty mentor within their academic department, and then put together a research proposal under the guidance of the faculty mentor. This had to be submitted to the undergraduate studies committee/office within a certain timeline. The honors and undergraduate research program would provide feedback to the students in terms of its feasibility and suitability as undergraduate research. Any requirements in terms of handling live animals, ethics, biosafety as well as the needed training and certification would be usually particularly stressed. Once approved, the student would develop a timeline of tasks for two consecutive semesters with guidance from the faculty mentor, and get started with the training/activities right away. During both semesters a number of university-level deadlines were imposed that included completing individual chapters such as the introductory, literature reviews, etc. as well as monthly progress reports and contingency plans. During the second (final) semester, students needed to submit close-to-final drafts of their honors thesis to the Division of Student Affairs for critique and feedback. Once approved after a number of revisions, students would provide formal copies to their advisor as well as disseminate their work through appropriate avenues such as poster/papers and/or public college or department-level presentations. During their graduation ceremony, they would be conferred the title of an 'Undergraduate Research Scholar' in their diploma as well as be provided with additional attire-related artefacts.

This group of students was in general a very motivated and self-disciplined set of youngsters who had a relatively clear plan and expectations about their research project. Student projects ranged from those having major hands-on components such as device/instrumentation design, prototyping, experimentation and validation, as well as those including hypothesizing and fundamental research, some even as part of National Science Foundation (NSF) grants. Altogether, this group of students expressed very positive attitudes as well as feedback of their experiences and was proud to show off their research accomplishments, especially their honors thesis and/or prototypes. Further, they were reinforced in their pursuit of graduate school, knowing that now there had an even better chance of graduate school admission due to this research experience. 


\section{Feedback and Conclusions}

The feedback from these various forms of undergraduate research programs and student participants involved was overwhelmingly positive; assessment instruments were one-on-one faculty observation as well as formal/informal surveys. In particular, the more involved students that completed projects over longer time periods (a semester or more) seemed to benefit from it significantly since they got to experience some of the inevitable and unscheduled delays and uncertainties inherent to the process and experience. They however obtained a new sense of satisfaction and achievement that they had contributed to actually progressing the technical field. There were no 'drop-outs' in these programs which is attributed to the self-motivated students getting involved on their own accord as well as because of clearly communicating the nature of research and the expectations and timelines. Also, students during their decision-making process of committing to the project got a chance to talk to their senior students who had completed the program successfully, and hence were able to become comfortable and confident to a certain extent beforehand.

To conclude, based on the positive feedback and experiences of the undergraduate students that completed various types of research programs, it can be said that undergraduate research for engineering technology students is definitely a beneficial and high-impact learning experience. Though not part of the standard engineering technology curriculum and though at first glance it does not seem to be an especially good fit for a hands-on/experiential degree, every student that had a research project experience benefitted from it as well as had a positive story to tell, that enhanced their undergraduate (and potentially future graduate) school experience. In general, the longer timeframes spent on a research project benefited them more as well as when working within a diverse but complementing research group. Most beneficial was the honors thesis program that emulated a master's thesis experience. These experiences follow literature and recommendations on undergraduate research as high-impact learning experiences. The challenging part is to recruit and motivate students into a research program that is not as standard part of the curriculum.

\section{Future Changes and Assessment}

In order to incentivize undergraduate research activities in an engineering technology curriculum, a new elective option has been recently instituted within the department. Students are required to take and successfully complete 2 technical electives as part of their engineering technology degree; so far, this requirement had been fulfilled via a standard set of departmental or external courses. Recently, a 400-level research credit option has been approved within the department to satisfy one of the technical elective requirements. Very similar to the honors thesis program, this includes some of the major components of research such as submitting and obtaining approval of a research proposal, progress reports, and major final deliverables such as a thesis report and public presentation. In addition to approval by the faculty mentor, the proposal and reports will require overseeing and approval by an independent faculty committee as well, much like a graduate thesis committee. The effectiveness of such an option is currently being assessed in terms of providing a high-impact learning experience to engineering technology students. Students will be made aware of this option and its benefits at an early stage of their degree program so that it will help recruitment efforts, and so that students could plans accordingly as well. Additionally, there is a plan to evaluate how such an experience could help prepare them for their capstone projects, as well as to track whether they continued on to enroll into a graduate program.

\section{Proceedings of the 2017 ASEE Gulf-Southwest Section Annual Conference \\ Organized by The University of Texas at Dallas \\ Copyright @ 2017, American Society for Engineering Education}




\section{References}

1. Zhan, W., Lam, A., "Benefits of Research Experience for Undergraduate Engineering Technology Students", Proceedings of the 2011 American Society for Engineering Education Annual Conference \& Exposition.

2. Robertson, K. "An Authentic Research Experience for Undergraduates on a Budget: Using Data From Simple Experiments to Develop Mini-Research Proposals", Journal of College Science Teaching, 46(2), pp. 32-36.

3. Stanford, J., Rocheleau, S., Smith, K., Mohan, J., "Early undergraduate research experiences lead to similar learning gains for STEM and Non-STEM undergraduates", Studies in Higher Education, 42(1), pp. 115-129.

4. Reisel, J., Cancado, L., Mitrayani, D., "Defining a Successful Undergraduate Research Experience in Engineering", Proceedings of the 2015 American Society for Engineering Education Annual Conference \& Exposition.

5. Branch, S., Woodcock, A., Graziano, W., "Person Orientation and Encouragement: Predicting Interest in Engineering Research", Journal of Engineering Education, 104 (2), pp. 119-138.

6. Altruger-Genc, G., Issapour, M., Zoghi, B., Radu, M., Hung, J., Islam, N., Ghadyahi, H., "Learning by Research: A Review of Undergraduate Research Experience in the School of Engineering Technology", Proceeding of the 2016 ASEE Mid-Atlantic Annual Conference.

7. Okhio, C., Misoc, F, Asgill, A., "Incorporating Training In Research \& Research Methods into the Undergraduate Curriculum in Engineering and Engineering Technology-(E\&ET)", Proceedings of the 2015 American Society for Engineering Education Annual Conference \& Exposition.

8. Foroudastan, S., Posey, J., "Undergraduate Research and Development Explores new Technologies in Energy Conservation Innovations", Proceedings of the 2014 American Society for Engineering Education Annual Conference \& Exposition.

9. $\quad$ Chickamenahalli, S., Barker, C., Khodor, A., "Effective Research Experience of Electrical Engineering Technology Students", Proceedings of the 1998 FIE Conference.

10. Yeh, C-P., Drew, J., Rockwell, C., Chien, H-C., "Undergraduate Research Projects for Engineering Technology Students", Proceedings of the 2003 American Society for Engineering Education Annual Conference \& Exposition.

11. Hseih, S., Research Experiences for Undergraduates in Mechatronics, Robotics, and Automated System Design”, Proceedings of the 2015 American Society for Engineering Education Annual Conference \& Exposition. 